Claremont Colleges

Scholarship@ Claremont

All HMC Faculty Publications and Research

HMC Faculty Scholarship

$1-1-1996$

\title{
An NMR Investigation of the Effect of Hydrogen Bonding on the Rates of Rotation about the C-N Bonds in Urea and Thiourea
}

\author{
Karl A. Haushalter \\ Harvey Mudd College \\ Janice Lau \\ California Institute of Technology \\ John D. Roberts \\ California Institute of Technology
}

\section{Recommended Citation}

K. A. Haushalter, J. Lau, and J. D. Roberts. 1996. An NMR Investigation of the Effect of Hydrogen Bonding on the Rates of Rotation about the C-N Bonds in Urea and Thiourea. J. Amer. Chem. Soc. 118: 8891-8896. DOI: 10.1021/ja961380k

This Article is brought to you for free and open access by the HMC Faculty Scholarship at Scholarship @ Claremont. It has been accepted for inclusion in All HMC Faculty Publications and Research by an authorized administrator of Scholarship @ Claremont. For more information, please contact 


\title{
An NMR Investigation of the Effect of Hydrogen Bonding on the Rates of Rotation about the $\mathrm{C}-\mathrm{N}$ Bonds in Urea and Thiourea
}

\author{
Karl A. Haushalter, Janice Lau, and John D. Roberts* \\ Contribution No. 9151 from the Gates and Crellin Laboratories of Chemistry, California Institute \\ of Technology, Pasadena, California 91125
}

Received April 26, $1996^{\otimes}$

\begin{abstract}
The interaction between urea and tetrabutylammonium acetate was investigated in dimethylformamide/ dimethyl sulfoxide solutions using ${ }^{1} \mathrm{H}$ and ${ }^{15} \mathrm{~N}$ NMR. The chemical-shift behavior of the urea protons is consistent with a urea-acetate hydrogen-bonded complex involving both carboxylate oxygens and the urea hydrogens trans to the carbonyl oxygen with $K_{\text {assoc }}=120 \pm 10$. Line shape analysis of the temperature-dependent ${ }^{1} \mathrm{H}$ NMR spectra show that $\Delta G^{\ddagger}$ for rotation about the $\mathrm{C}-\mathrm{N}$ bond of urea changes only slightly from $11.0 \pm 0.1$ to $11.2 \pm 0.1$ $\mathrm{kcal} / \mathrm{mol}$ on 1:1 molar addition of tetrabutylammonium acetate to a dilute solution of urea. A parallel investigation of the interaction of thiourea with tetrabutylammonium acetate gave a binding constant, $K_{\text {assoc }}=90 \pm 10$. The $\Delta G^{\ddagger}$ for rotation about the $\mathrm{C}-\mathrm{N}$ bond of thiourea was found to increase from $13.5 \pm 0.1$ to $14.0 \pm 0.1 \mathrm{kcal} / \mathrm{mol}$ on $1: 1$ addition of tetrabutylammonium acetate to a dilute solution of thiourea in dimethylformamide/dimethyl sulfoxide. Measurements were also made of the self-association of several ureas and of $\Delta G^{\ddagger}$ for rotation about both $\mathrm{C}(\mathrm{O})-\mathrm{N}$ bonds of 1,1-dimethylurea.
\end{abstract}

\section{Introduction}

Dynamic NMR has been used extensively to study the rotation about the $\mathrm{C}(\mathrm{O})-\mathrm{N}$ bonds in amides, with results generally consistent with the resonance interpretation of the delocalization of the nitrogen electron lone-pair to form a partial double bond between nitrogen and the carbonyl carbon. ${ }^{1}$ The theoretical energy barriers for rotation about amide bonds calculated by $a b$ initio procedures are usually lower than those determined by experiment. ${ }^{2}$ Recently, Wiberg and co-workers ${ }^{2}$ have indicated that the discrepancy between theory and experiment can be accounted for by solvent-amide interactions as the result of investigation of the solvent-dependence of the rotational barriers of dimethylacetamide and dimethylformamide using NMR. The activation barriers for rotation were found to depend on solvent polarity and the relationship was reasonably straightforward, except for hydrogen-bonding solvents. Preliminary work suggested that the $a b$ initio methods can be revised to correct for hydrogen bonding, but that work was not complete. ${ }^{2}$ Drakenberg and co-workers have shown that hydrogen bonding could be responsible for up to $2-3 \mathrm{kcal} / \mathrm{mol}$ of the barrier to rotation of amides in hydrogen-bonding solvents. ${ }^{3}$

The $a b$ initio calculated barriers for rotation of ureas are like those for amides, lower than the experimentally determined barriers (Tables 1 and 2). Here, also, solvent interactions have been suggested to be responsible for the experimental barriers being 3-4 $\mathrm{kcal} / \mathrm{mol}$ larger than the theoretical barriers. Unfortunately, the study of a variety of solvent effects on the rate of rotation about the $\mathrm{C}-\mathrm{N}$ bond of urea itself is made difficult by the low solubility of urea in many organic solvents. So far (see Table 1), urea has been investigated in dimethylformamide, dimethylformamide/acetone, acetone/tetramethylurea, and di-

${ }^{\otimes}$ Abstract published in Advance ACS Abstracts, September 1, 1996.

(1) Oki, M. Applications of Dynamic NMR Spectroscopy to Organic Chemistry; VCR Publishers, Inc.: Deerfield, 1985; pp 41-67.

(2) Wiberg, K. B.; Rablen, P. R.; Rush, D. J.; Keith, T. A. J. Am. Chem. Soc. 1995, 117, 4261-4270.

(3) Drakenberg, T.; Dahlqvist, K. J.; Forsen, S. J. J. Phys. Chem. 1972, $76,2178-2183$
Table 1. Earlier Determinations of $\Delta G^{\ddagger}$ for Rotation about the $\mathrm{C}-\mathrm{N}$ Bonds of Urea

\begin{tabular}{lcr}
\hline \multicolumn{1}{c}{ solvent } & $\Delta G^{\ddagger}, \mathrm{kcal} / \mathrm{mol}$ & ref \\
\hline DMF/DMSO $^{a}$ & $11.5 \pm 0.1$ & 16 \\
acetone/TMU $^{b}$ & $11.4 \pm 0.1$ & 16 \\
DMF & $11.2 \pm 0.1$ & 16 \\
DMF/acetone & 11.0 & 8 \\
DMF/DMSO & 11.2 & 10 \\
\hline
\end{tabular}

${ }^{a} \mathrm{DMF}=N, N$-dimethylformamide, DMSO $=$ dimethyl sulfoxide. ${ }^{b} \mathrm{TMU}=$ tetramethylurea.

Table 2. Theoretical Calculations of $\Delta G^{\ddagger}$ for Rotation about the $\mathrm{C}-\mathrm{N}$ Bonds of Urea

\begin{tabular}{lcc}
\hline \multicolumn{1}{c}{ ab initio method } & $\Delta G^{\ddagger}, \mathrm{kcal} / \mathrm{mol}$ & ref \\
\hline DFT & 7 & 17 \\
MP-2/6-31G* & 8 & 18 \\
MP-2/6-31G* & 8.1 & 19 \\
MP-2/6-31G* + ZPE & 7.4 & 19 \\
\hline
\end{tabular}

methylformamide/dimethyl sulfoxide solutions. Across this limited range of solvents, there is little variation in the rotational barriers. Furthermore, while many amides are volatile enough to allow barriers to be measured in the gas-phase by NMR, urea is not sufficiently volatile to do gas-phase NMR at reasonable temperatures. However, there is ample reason to expect that protonation, hydrogen bonding, or complexation with Lewis acids to the carbonyl oxygen of ureas should increase the barriers to rotation about the $\mathrm{C}(\mathrm{O})-\mathrm{N}$ bonds. ${ }^{4}$ What is less clear, is the influence of hydrogen bonding where the amide or urea is acting as the proton donor and this is the major thrust of this investigation.

We have investigated the interaction of acetate ion with urea and thiourea following the report by Hamilton and co-workers that 1,3-dimethylurea forms trans bidentate hydrogen bonds with

(4) Martin, M. L.; Filleux-Blanchard, M. L.; Martin, G. J.; Webb, G. A Org. Magn. Reson. 1980, 13, 396-402. This paper contains an excellent summary of the dynamic NMR of ureas, thioureas, and their Lewis acid adducts. 


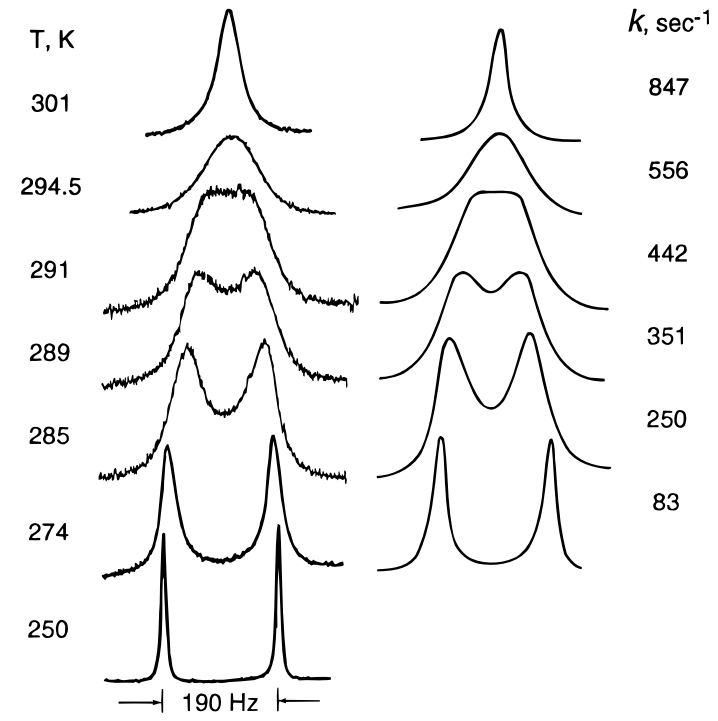

Figure 1. Temperature dependence of the ${ }^{1} \mathrm{H}$ resonances of $100 \mathrm{mM}$ thiourea in dimethylformamide/deuteriodimethyl sulfoxide solution. Experimental spectra on the left and calculated on the right, with rate constants $1 / \tau \mathrm{s}$.

acetate in DMSO as shown by $\mathbf{1 .}^{5}$ This observation is of considerable interest because of substantial complex formation even in a strongly competitive hydrogen-bonding solvent such as DMSO. The aim of the present study was to determine the effect of the expected acetate binding, as 2, 3, on the rate of rotation about the $\mathrm{C}-\mathrm{N}$ bonds of urea and thiourea. Because the protons of thiourea are more acidic than those of urea, tighter binding should be expected for 3 than for $2 .^{5}$ Thus, changes in the rotational barrier for urea caused by acetate association was expected to be amplified with thiourea bound to acetate.

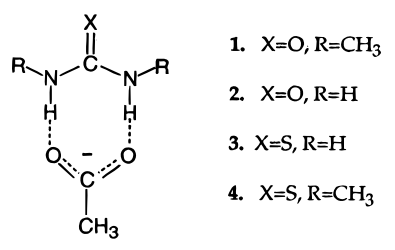

In addition to providing theoretical insight into the effect of hydrogen-bonding on the rotation rates about the $\mathrm{C}-\mathrm{N}$ bonds of ureas, the urea-carboxylate bonding motif is of interest for the attention it has received as a structural element in new molecular catalysts. ${ }^{6}$ Urea-carboxylate interactions have also been studied as mimics of the carboxylate-binding pocket of antibiotics such as ristocetin. ${ }^{7}$

\section{NMR Spectra of Urea and Thiourea}

Figure 1 shows a typical temperature-dependent ${ }^{1} \mathrm{H}$ spectra, here of thiourea. Analogous spectra were observed for urea and 1,1-dimethylurea. At room temperature, rotation about the $\mathrm{C}(\mathrm{O})-\mathrm{N}$ bonds is typically rapid and a single, time-averaged peak is observed. As the temperature is lowered, the rotation becomes slower and separate resonances appear for the $\mathrm{N}-\mathrm{H}$ (or the $\mathrm{N}-\mathrm{CH}_{3}$ protons) trans and cis to the oxygen/sulfur. For all of these substances, the downfield signal was assigned to the $\mathrm{N}-\mathrm{H}$ protons in the trans position. This assignment is

(5) Fan, E.; Van Arman, S. A.; Kincaid, S.; Hamilton, A. D. J. Am. Chem. Soc. 1993, 115, 369-370.

(6) Smith, P. S.; Reddington, M. V.; Wilcox, C. S. Tetrahedron Lett. 1992, 33, 6085-6088. 7366.

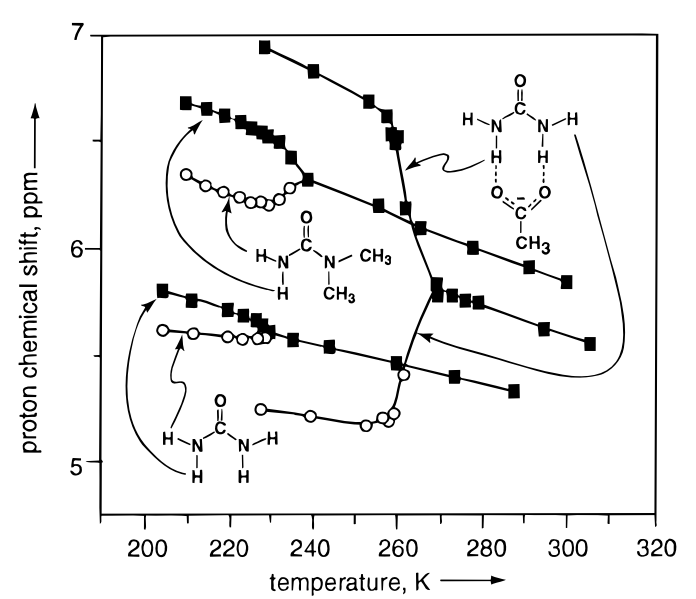

Figure 2. Temperature dependences of the ${ }^{1} \mathrm{H}$ NMR N-H chemical shift for urea, urea-acetate and 1,1-dimethylurea. All shifts measured relative to the dimethylformamide formyl resonance at $8.03 \mathrm{ppm}$. The points are $(\mathbf{\square})$ and $(O)$ correspond to trans- and cis-urea protons, respectively. Urea was $15 \mathrm{mM}$ and with $15 \mathrm{mM}$ acetate in $80 \%$ dimethylformamide $/ 20 \%$ deuteriodimethyl sulfoxide solution, while the 1,1-dimethylurea was $100 \mathrm{mM}$ in dimethylformamide- $d_{7}$.

opposite to that suggested by Walter, Rose, and Schaumann, ${ }^{8}$ but is made to accord with the assignments in formamide that are based on relative coupling constants. ${ }^{9}$ However, if one extrapolates the changes in shift of the separate $\mathrm{N}-\mathrm{H}$ protons with temperature for urea beyond the coalescence point (see Figure 2) to room temperature, the shifts there could well be reversed.

Plots of chemical shifts versus temperature are shown in Figures 2-4 for urea, 1,1-dimethylurea, and thiourea. In the low-temperature regime, the trans $\mathrm{N}-\mathrm{H}$ proton resonance of urea and thiourea (downfield) are shifted greatly ( $>1 \mathrm{ppm}$ ) downfield by addition of tetrabutylammonium (TBA) acetate. This large shift is an indicator of substantial hydrogen bonding as expected for $\mathbf{2}$ and $\mathbf{3}$. In contrast, the cis proton resonances are not shifted downfield by addition of acetate-indeed, they are shifted significantly upfield.

Further support for $\mathbf{2}$ comes from the chemical-shift changes with acetate binding to 1,1-dimethylurea and 2-imidazolidone. These substances cannot bind to acetate in the same way as urea, but could be expected to be able to form hydrogen-bonds as in $\mathbf{5}$ and $\mathbf{6}$.

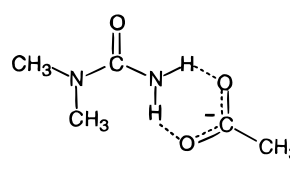

5

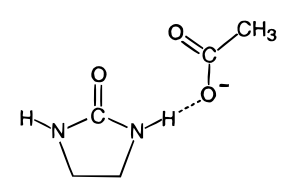

6
For 2-imidazolidone, the $\mathrm{N}-\mathrm{H}$ proton shift at room temperature was compared for two 50-mM 2-imidazolidone solutions in $80 \%$ dimethylformamide $/ 20 \%$ dimethyl sulfoxide- $d_{6}$, one containing two equivalents of TBA acetate. The added acetate shifted the $\mathrm{N}-\mathrm{H}$ resonance from 6.11 to $6.28 \mathrm{ppm}$ (referenced to the dimethylformamide formyl proton resonance). The downfield change in shift of $0.17 \mathrm{ppm}$ is small, compared to the downfield shift of $0.91 \mathrm{ppm}$ for the extrapolated $\mathrm{N}-\mathrm{H}$ chemical shifts of the trans proton of less-concentrated $(15 \mathrm{mM})$ urea with, and without, one equivalent of TBA acetate. Even

(8) Walter, W.; Schaumann, E.; Rose, H. Tetrahedron 1972, 28, 32333239.

(9) Sunners, B.; Piette, L. H.; Schneider, W. G. Can. J. Chem. 1960, $36,681-688$. 


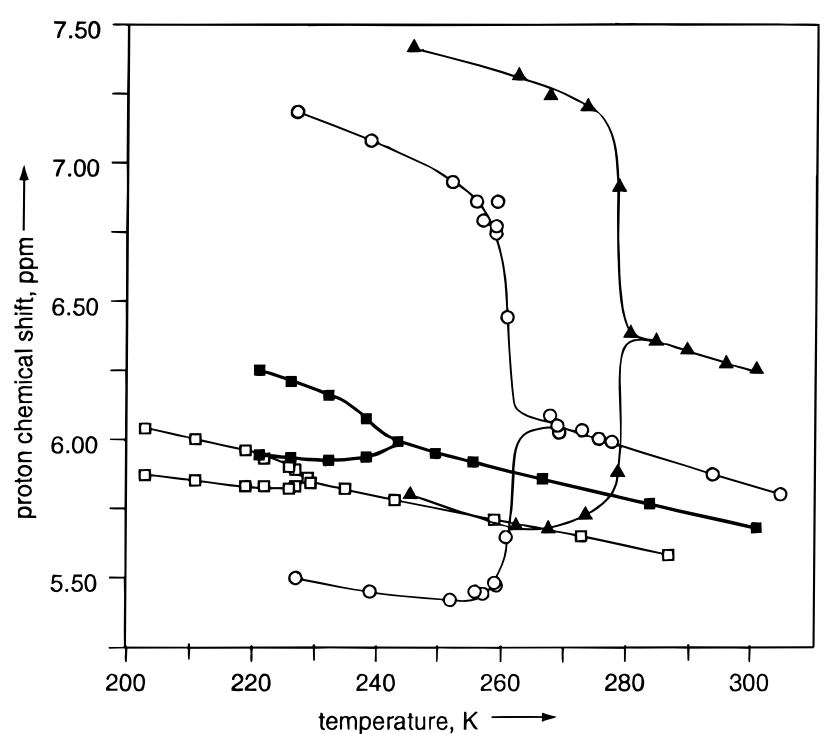

Figure 3. Temperature dependences of the ${ }^{1} \mathrm{H}$ NMR N-H chemical shift for urea, urea-acetate with different acetate concentrations. All shifts measured relative to the dimethylformamide formyl resonance at $8.03 \mathrm{ppm}$. The points for urea are $(\square)$ for $0.15 \mathrm{mM}$, (O) for 0.15 $\mathrm{mM}$ with $0.15 \mathrm{mM}$ acetate, (ם) for $500 \mathrm{mM}$ and (A) for $500 \mathrm{mM}$ with $500 \mathrm{mM}$ acetate in $80 \%$ dimethylformamide/20\% deuteriodimethyl sulfoxide solution.

more to the point is the fact that the extrapolated shift of the cis protons of urea, which are structurally analogous to the 2-imidazalone $\mathrm{N}-\mathrm{H}$ protons, in the presence of acetate are upfield by about $0.4 \mathrm{ppm}$ in comparison with the extrapolated shift without added acetate.

The chemical-shift behavior of 1,1-dimethylurea was also investigated. Two samples of 1,1-dimethylurea were made, both $50 \mathrm{mM}$ in 1,1-dimethylurea in $80 \%$ dimethylformamide/20\% dimethyl sulfoxide- $d_{6}$. One of the two samples also contained $100 \mathrm{mM}$ TBA acetate. At room temperature, the addition of acetate shifted the averaged $\mathrm{N}-\mathrm{H}$ resonance of 1,1-dimethylurea downfield by $0.11 \mathrm{ppm}$ (which compares to $0.30 \mathrm{ppm}$ for urea and 1 equiv of acetate). More important are the low-temperature results where the 1,1-dimethylurea trans- and cis- $\mathrm{N}-\mathrm{H}$ protons were found to be shifted downfield by 0.13 and $0.05 \mathrm{ppm}$, respectively, with added acetate. For comparison, with urea at low temperature the downfield shift of the trans proton caused by acetate addition is $1.29 \mathrm{ppm}$. The cis proton is actually shifted upfield by $0.33 \mathrm{ppm}$ by acetate addition. The lack of a substantial downfield shift caused by acetate for the $\mathrm{N}-\mathrm{H}$ resonances of 1,1-dimethylurea suggests that any hydrogen bonding between 1,1-dimethylurea and acetate is weaker than between urea and acetate.

\section{Self-Association}

Because urea is not sufficiently soluble to study selfassociation in non-polar solvents, 1,3-dimethylurea was used as a model compound. Figure 5 shows the concentration dependence of the chemical shift of the $\mathrm{N}-\mathrm{H}$ protons of 1,3dimethylurea in chloroform- $d$ referenced to TMS. Figure 5 also shows the results of an analogous experiment using $80 \%$ dimethylformamide/20\% dimethyl sulfoxide- $d_{6}$ as solvent. Here, the concentration dependence of the chemical shift is almost completely muted by the solvent interaction and the chemical shift is almost constant at $\sim 5.8 \mathrm{ppm}$. It is interesting that the shift in dimethylformamide is not far from the high concentration shift (5.75 ppm) in chloroform- $d$ and also is quite close to the $5.65 \mathrm{ppm}$ proton shift of 1,3-dimethylurea in water. The similarity of these shifts seems to indicate that self-

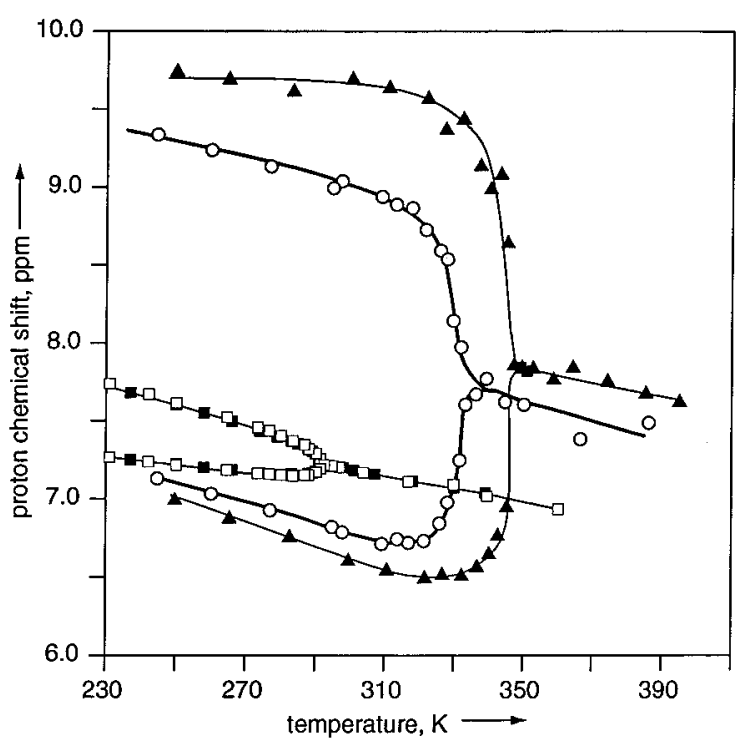

Figure 4. Temperature dependence of the ${ }^{1} \mathrm{H}$ NMR N-H chemical shift for $15 \mathrm{mM}$ thiourea in $80 \%$ dimethylformamide- $d_{7} / 20 \%$ dimethyl sulfoxide- $d_{6}$ solution. All shifts measured relative to the DMF formyl resonance at $8.03 \mathrm{ppm}$. The points for thiourea are $(\square)$ for $0.15 \mathrm{mM}$, (O) for $0.15 \mathrm{mM}$ with $0.15 \mathrm{mM}$ acetate, $(\boldsymbol{\square})$ for $100 \mathrm{mM}$ and (A) for $100 \mathrm{mM}$ with $100 \mathrm{mM}$ acetate in $80 \%$ dimethylformamide/20\% deuteriodimethyl sulfoxide solution.

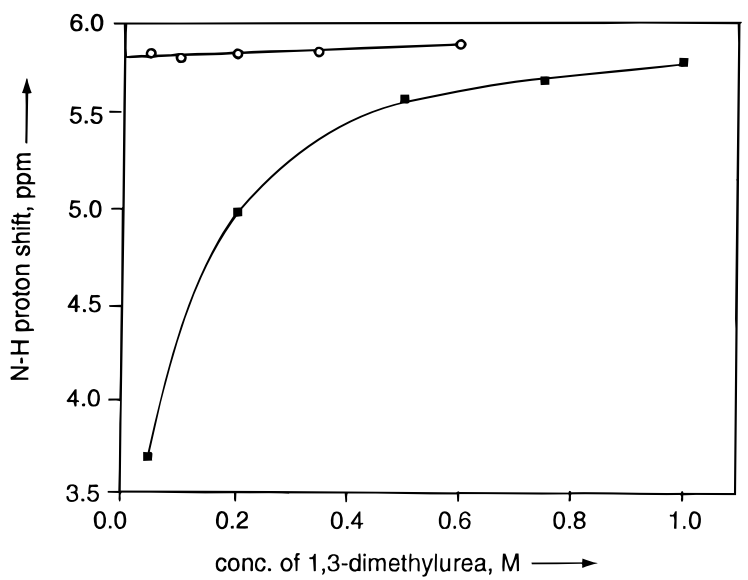

Figure 5. The concentration dependence of the proton chemical shifts of 1,3-dimethylurea; ( $\mathbf{\square})$ for chloroform- $d$ and $(O)$ for $80 \%$ dimethylformamide $/ 20 \%$ dimethyl sulfoxide- $d_{6}$. Shifts measured relative to TMS.

association and interaction with a good hydrogen-bond accepting solvent have substantially the same effect on the $\mathrm{N}-\mathrm{H}$ proton chemical shifts of 1,3-dimethylurea.

The slopes of the changes in proton shift with temperature in the fast-rotation regime are rather uniform and amount to about -4 to $-10 \mathrm{ppb} / \mathrm{K}$ for urea and 1,1-dimethylurea, Figures 2 and 3, as well as thiourea, Figure 4. Earlier, the suggestion was made that an important part of the shift change with temperature for urea could arise from temperature changes in the magnitude of torsional oscillations about the $\mathrm{C}-\mathrm{N}$ bond. ${ }^{10}$ The evidence reported here suggests that changes in hydrogen bonding are likely to be more important, even though it is well established that smaller shift changes with temperature occur where hydrogen bonding is not important, as for $\mathrm{N}, \mathrm{N}$-dialkylamides. ${ }^{11}$ In the first place, the changes in shift with temperature are in the direction expected for increasing hydrogen

(10) Zhao, Y.; Raymond, M. K.; Tsai, H.; Roberts, J. D. J. Phys. Chem. 1993, 97, 2910-2913.

(11) Reeves, L. W.; Shaddick, R. C.; Shaw, K. N. Can. J. Chem. 1971, $49,3684-3690$. 
bonding with decreasing temperature and are within a factor of two of those observed for the temperature-dependent hydrogen bonding shift changes of ethanol and 1,2-ethanediol ${ }^{12}$ and do not differ greatly from the -6 to $-10 \mathrm{ppb} / \mathrm{K}$ for the temperature coefficients of amide proton resonances in extended-chain peptide and protein structures and the smaller temperature coeefficients of about $-4 \mathrm{ppb} / \mathrm{K}$ for amides not accessible to solvent or hydrogen bonded in tighter protein environments. ${ }^{13}$ Second, although, as mentioned earlier, the slopes of the shift changes with temperature do not differ much, the intercepts do change substantially with concentration. Third, as Figures 2-4 show, the cis and trans protons do not have the same slopes, which is consistent with differential hydrogen bonding involving these different types of protons. Finally, the constancy of the shifts of the trans-protons of thiourea in the slow-rotation regime, as seen in Figure 4, when complexed with the higher concentration of acetate ion, indicates saturation of the hydrogenbonding below about $310 \mathrm{~K}$. With the lower concentration of acetate ion, saturation is not evident, and the shift to lower field continues as the temperature is decreased.

Figure 2 shows that the change in shift with temperature of 1,1-dimethylurea is almost twice that of urea itself as is consistent with a surprising larger $\Delta H$ for association with the solvent, or self-association, involving the dimethyl compound.

Comparision of Figures 3 and 4 shows that there is an apparent difference in behavior of urea and thiourea with temperature as a function of concentration. Thus for thiourea, the 15 and $100 \mathrm{mM}$ correlation lines, with no acetate, overlap almost completely while, with urea, the 15 and $500 \mathrm{mM}$ concentration curves have different intercepts and different separations in the slow-rotation regime but essentially the same slopes. These differences are expected, at least in part, to be the result of self-association, and because self-association will depend on the square of the concentrations, assuming other things are the same, changes in the positions of the urea signals at $500 \mathrm{mM}$ compared to those of thiourea at $100 \mathrm{mM}$ could be enhanced by a factor of 25. Presumably, thiourea would show similar behavior at $500 \mathrm{mM}$ concentrations.

\section{Urea and Thiourea Binding to Acetate}

Binding constants were determined experimentally for ureaacetate and thiourea-acetate binding by measuring the chemical shift changes of solutions in $80 \%$ dimethylformamide/20\% dimethyl sulfoxide- $d_{6}$ with constant amounts of (thio)urea and varying amounts of tetrabutylammonium acetate at $298 \mathrm{~K}$. The resulting isotherms are shown in Figure 6. The equilibrium constants, $K_{\text {assoc }}$, obtained by nonlinear regression using an iterative computer program written in True BASIC, were 120 for urea binding to acetate $(\Delta G=-2.8 \mathrm{kcal} / \mathrm{mol})$ and 90 for thiourea binding to acetate $(\Delta G=-2.6 \mathrm{kcal} / \mathrm{mol})$.

The difference in relative stabilities of $\mathbf{2}$ and $\mathbf{3}$ is quite small and surprising considering that Hamilton and co-workers ${ }^{5}$ observed an almost 10-fold greater stability of the 1,3dimethylthiourea complex 4 over the urea complex 1. This was rationalized by the greater acidity of the thiourea protons. ${ }^{5}$ With $\mathbf{2}$ and $\mathbf{3}$, not only is the difference in stability small but also urea appears to form the more stable complex. However, the effect seems too small to permit a convincing rationalization.

\section{Barriers to Rotation}

Complete line shape analysis of the NMR spectra of urea and thiourea provided rates of rotation. Computer-generated

(12) Martin, M. L.; Martin, G. J.; Delpeuch, J.-J. Practical NMR Spectroscopy; Heyden: Philadelphia, PA, 1980; pp 445-446.

(13) Deslauriers, R.; Smith, I. C. P., Biological Magnetic Resonance; Berliner. L. J., Reuben, J., Eds.; Plenum Press: New York, 1980; Vol. 2, pp 243-344. line shapes and the determined rate constants for rotation appear alongside the experimental spectra in Figure 1. Straightforward applications of the Eyring equation and the Arrhenius equation provided the energy parameters summarized in Table 3.

Our values for the $\Delta G^{\ddagger}$ for urea are in good agreement with previous results as Tables 1 and 3 reveal. The $\Delta G^{\ddagger}$ of 13.5 $\mathrm{kcal} / \mathrm{mol}$ for thiourea rotation in the absence of acetate is slightly larger than the previously reported values, which range from $12.0 \mathrm{kcal} / \mathrm{mol}$ in acetonitrile ${ }^{8}$ to $13.1 \mathrm{kcal} / \mathrm{mol}$ in pyridine- $d_{5} .{ }^{14}$

It is interesting that we and Martin and co-workers ${ }^{4}$ despite substantial differences in coalescence temperatures, find that $\Delta G^{\ddagger}$ for rotation about the $\mathrm{C}(\mathrm{O})-\mathrm{N}\left(\mathrm{CH}_{3}\right)_{2}$ bond $(11.0 \mathrm{kcal} /$ $\left.\mathrm{mol}, 10.6 \mathrm{kcal} / \mathrm{mol}^{4}\right)$ of 1,1-dimethylurea in dimethylformamide$d_{7}$ solution is nearly the same as for the $\mathrm{C}(\mathrm{O})-\mathrm{NH}_{2}$ bond $(10.6$ $\left.\mathrm{kcal} / \mathrm{mol}, 9.8 \mathrm{kcal} / \mathrm{mol}^{4}\right)$. Such is not the case for dimethylformamide ${ }^{15}$ and formamide, ${ }^{16}$ where the barrier for dimethylformamide is $4 \mathrm{kcal} / \mathrm{mol}$ larger (although there are differences in solvent). This difference is expected because a $-\mathrm{N}\left(\mathrm{CH}_{3}\right)_{2}$ group should be better able to accommodate a positive charge resulting from delocalization of its electron pair than a $-\mathrm{NH}_{2}$ group (thus $\Delta \sigma_{\mathrm{R}}{ }^{+}$of the $-\mathrm{NH}\left(\mathrm{CH}_{3}\right)_{2}$ group is -1.75 and that of the $-\mathrm{NH}_{2}$ group is -1.61$) .{ }^{17}$ The smaller difference with 1,1 dimethylurea is sure to be the result of steric hindrance as also befits the substantially lower barrier to rotation around the $\mathrm{C}(\mathrm{O})-\mathrm{N}$ bonds than for urea or thiourea. If the steric interaction between the trans hydrogen on the $-\mathrm{NH}_{2}$ group and the trans methyl of the $-\mathrm{N}\left(\mathrm{CH}_{3}\right)_{2}$ group turns the methyl out of the $\mathrm{C}-\mathrm{N}$ $\mathrm{C}(\mathrm{O})-\mathrm{N}-\mathrm{H}$ plane, then the delocalization of the lone pair of the nitrogen connected to that methyl will be diminished and that of the $-\mathrm{NH}_{2}$ lone pair will be increased. A priori, one might expect that the $\mathrm{NH}_{2}$ group would be easier to push out of the plane. However, this could be more inimical for the $\mathrm{NH}_{2}$ group as far as hydrogen-bonding to DMSO-DMF than would for the $-\mathrm{N}\left(\mathrm{CH}_{3}\right)_{2}$ group. The result would be an increase in $\Delta G^{\ddagger}$ for rotation around the $\mathrm{C}(\mathrm{O})-\mathrm{NH}_{2}$ bond. The reverse situation is observed for ureas when the steric hindrance is less and for 1-methylurea ( $87 \%$ with the methyl cis to the oxygen), the $\Delta G^{\ddagger}$ for rotation around the $\mathrm{C}(\mathrm{O})-\mathrm{NH}_{2}$ bond is about $9.8 \mathrm{kcal} / \mathrm{mol}$, while $\Delta G^{\ddagger}$ for rotation from the cis to the trans configuration of the $\mathrm{C}(\mathrm{O})-\mathrm{NH}\left(\mathrm{CH}_{3}\right)$ bond is $12.3 \mathrm{kcal} / \mathrm{mol}^{4}$

Only small increases in $\Delta G^{\ddagger}$ (less than $1 \mathrm{kcal} / \mathrm{mol}$ ) were observed with added acetate for both urea and thiourea. A larger increase in $\Delta G^{\ddagger}$ might be expected on addition of acetate on the basis that rotation would require breaking of at least one bond in the trans bidentate complex. However, much depends on the position of equilibrium for $\mathbf{2}$ and $\mathbf{3}$ relative to the monodentate bonding as 7 .
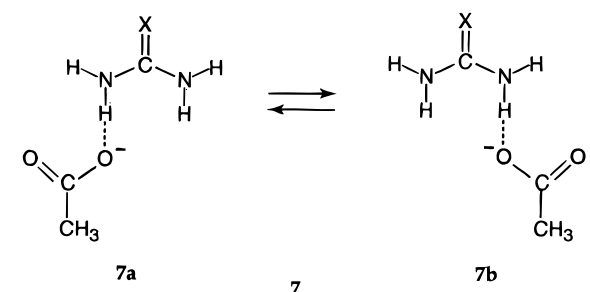

The fact of the matter is that there is no compelling evidence that $\mathbf{2}$ and $\mathbf{3}$ are much more stable than $\mathbf{7 a}$ and $\mathbf{7 b}$. The NMR evidence can only tell us that, if $\mathbf{7 a}$ and $\mathbf{7 b}$ are present, they must be in rapid equilibrium. One could argue that, if monodentate $\mathbf{7 a}$ and $\mathbf{7 b}$ are important, then binding to the cis-

(14) Sullivan, R. H.; Price, E. Org. Magn. Reson. 1975, 7, 143-150.

(15) Rabinovitz, M.; Pines, A. J. Am. Chem. Soc. 1969, 91, 1585-1589.

(16) Drakenberg, T.; Forsen, S. J. Phys. Chem. 1970, 74, 1-7.

(17) Hine, J. Structural Effects on Equilibria in Organic Chemistry; John Wiley \& Sons: New York, NY, 1974; pp 80. 
Table 3. Energy Parameters for Rotation about the $\mathrm{C}(\mathrm{O})-\mathrm{N}$ Bonds of Urea, Thiourea and 1,1-Dimethylurea ${ }^{a}$

\begin{tabular}{|c|c|c|c|c|c|c|c|}
\hline urea, mM & thiourea, $\mathrm{mM}$ & TBA acetate, $\mathrm{mM}$ & $\Delta G^{\ddagger b}, \mathrm{kcal} / \mathrm{mol}$ & $\Delta H^{\ddagger}, \mathrm{kcal} / \mathrm{mol}$ & $\Delta S^{\ddagger}, \mathrm{cal} / \mathrm{mol} / \mathrm{deg}$ & $T_{\mathrm{c}}, \mathrm{K}$ & $E_{\mathrm{a}}, \mathrm{kcal} / \mathrm{mol}$ \\
\hline 15 & & & $11.0 \pm 0.1$ & $15 \pm 2$ & $17 \pm 9$ & 229 & $15 \pm 2$ \\
\hline 15 & & 15 & $11.2 \pm 0.1$ & $12 \pm 1$ & $1 \pm 5$ & 264 & $12 \pm 1$ \\
\hline 500 & & & $11.2 \pm 0.1$ & $12 \pm 4$ & $5 \pm 17$ & 240 & $13 \pm 4$ \\
\hline 500 & & $500^{c}$ & $11.7 \pm 0.1$ & $14 \pm 1$ & $9 \pm 6$ & 279 & $15 \pm 2$ \\
\hline & 15 & & $13.5 \pm 0.1$ & $14.1 \pm 0.9$ & $2 \pm 3$ & 291 & $14.6 \pm 0.9$ \\
\hline & 15 & 15 & $14.0 \pm 0.1$ & $14.3 \pm 0.9$ & $1 \pm 3$ & 333 & $14.9 \pm 0.9$ \\
\hline & 100 & & $13.5 \pm 0.1$ & $13 \pm 1$ & $-1 \pm 3$ & 291 & $13.9 \pm 0.9$ \\
\hline & 100 & 100 & $14.3 \pm 0.1$ & $15 \pm 1$ & $3 \pm 4$ & 347 & $16 \pm 1$ \\
\hline $15^{d}$ & & & $11.0 \pm 0.1$ & $6 \pm 1^{e}$ & $-20 \pm 4^{e}$ & 231 & $7 \pm 1$ \\
\hline $15^{f}$ & & & $10.6 \pm 0.1$ & $9 \pm 1$ & $-5 \pm 1$ & 238 & $9 \pm 1$ \\
\hline
\end{tabular}

${ }^{a}$ Except for 1,1-dimethylurea, all samples were in $80 \%$ DMF, $20 \%$ DMSO- $d_{6}$ or $80 \%$ DMF- $d_{7}$, $20 \%$ DMSO- $d_{6}$, uncertainties expressed at the $95 \%$ confidence level. ${ }^{b}$ Average values for $\Delta G^{\ddagger}$ are reported for $T_{\mathrm{c}} .{ }^{c}$ Tetramethylammonium acetate was substituted for tetrabutylammonium acetate. ${ }^{d}$ 1,1-Dimethylurea, data for rotation about the $\mathrm{C}(\mathrm{O})-\mathrm{N}\left(\mathrm{CH}_{3}\right)_{2}$ bond in DMF- $d_{7} .{ }^{e}$ These values are particularly subject to experimental error because the chemical-shift differences in the slow-rotation regime are smaller than for the $\mathrm{NH}_{2}$ groups. ${ }^{f} 1,1$-Dimethylurea, data for rotation about the $\mathrm{C}(\mathrm{O})-\mathrm{NH}_{2}$ bond in DMF- $d_{7}$.

hydrogens analogous to $\mathbf{6}$ should also be significant, but this would ignore both our experimental evidence on the NMR shift changes that occur on acetate binding to 2-imidazolidone and the greater acidity of the trans protons expected in analogy with the $E, Z$ equilibrium of carboxylic acids. ${ }^{18}$ However, it does seem that formation of $\mathbf{7 a}$ and $\mathbf{7 b}$ should act to decrease the barrier to rotation of the non-hydrogen bonded $\mathrm{NH}_{2}$ by altering the balance in the competitive conjugation of the two $\mathrm{NH}_{2}$ groups with the carbonyl group. Formation of a hydrogen bond to a hydrogen attached to nitrogen should release electron density to that nitrogen and thus enhance both electron delocalization of that nitrogen's lone pair and its barrier to rotation. But increased delocalization of the electron pair on this nitrogen would act to decrease the double-bond character of the nonacetate complexed $\mathrm{C}-\mathrm{N}$ bond. On this basis, it is perhaps not surprising that the increases in $\Delta G^{\ddagger}$ for rotation are not large, despite the substantial equilibrium constants for complexation.

The overall increase in $\Delta G^{\ddagger}$ with acetate concentration is as expected for equilibrium association. The rate of rotation of thiourea is slowed somewhat more by acetate than for urea, even though urea appears to form a slightly more stable complex with acetate. This difference could reflect differences in the equilibria for $\mathbf{2}$ and $\mathbf{3}$ with structures like $\mathbf{7 a}$ and $\mathbf{7 b}$.

There are trends in the other activation parameters (Table 3 ), but the substantial uncertainties preclude definitive conclusions. Generally, addition of acetate causes an increase in $\Delta H^{\ddagger}$. If the acetate complexes have structures $\mathbf{2}$ or $\mathbf{3}$, instead of $\mathbf{7 a}$ $\rightleftarrows \mathbf{7 b}$, then in order for rotation to occur, hydrogen bonds must be broken, so there should be a favorable activation entropy change and an activation enthalpy price to pay in going from 2 or $\mathbf{3}$ to the transition state. However, the values of $\Delta S^{\ddagger}$ do not seem to have a clear pattern, although one should expect increases on addition of acetate because, whether rotation occurs by the complexes $\mathbf{2}$ or $\mathbf{3}$ dissociating into two species, or by opening to $\mathbf{7 a}$ or $\mathbf{7 b}$, there should be more degrees of freedom to the transition state than in the ground-state acetate complex.

In this study of the hydrogen-bonding effects, solubility constraints required use of hydrogen-bond accepting solvents, specifically dimethylformamide/dimethyl sulfoxide. Obviously, hydrogen bonding to the solvent competes with hydrogen bonding of urea to acetate. However, the interactions of the ureas with the solvent are surely less effective than with acetate as is shown by the equilibrium constants for formation of $\mathbf{2}$ and $\mathbf{3}$ or of $\mathbf{7 a} \rightleftarrows \mathbf{7 b}$.

\section{6. ${ }^{15} \mathbf{N}$ Chemical Shifts}

For an alternative assessment of the effect of added acetate in solutions of urea, ${ }^{15} \mathrm{~N}$ NMR chemical shifts were measured

(18) Gandour, R. Bioorg. Chem. 1981, 1981, 169-176.

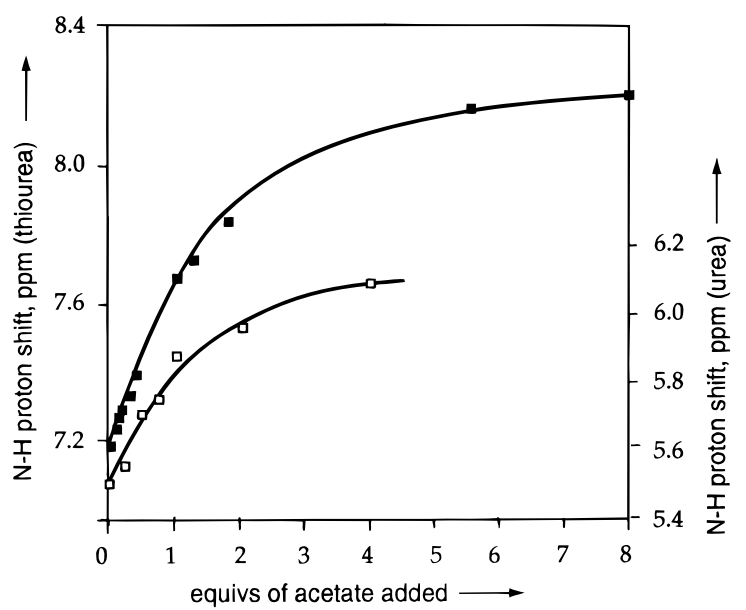

Figure 6. Binding isotherms at $298 \mathrm{~K}$ for $15 \mathrm{mM}$ urea ( $\square$, right-hand scale) and $15 \mathrm{mM}$ thiourea $(\boldsymbol{\square}$, left-hand scale) with acetate in $80 \%$ dimethylformamide/ $20 \%$ dimethyl sulfoxide- $d_{6}$. The proton shifts were referenced to TMS.

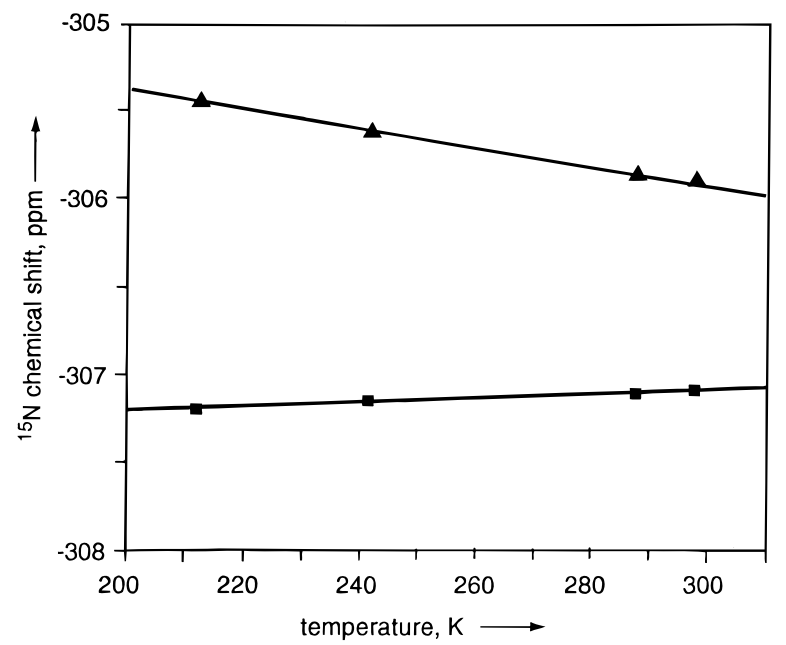

Figure 7. Temperature dependence of the ${ }^{15} \mathrm{~N}$ chemical shifts of 15 $\mathrm{mM}{ }^{15} \mathrm{~N}_{2}$-urea in $80 \%$ dimethylformamide/20\% dimethyl sulfoxide-

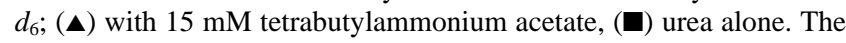
shifts are referenced to external $\mathrm{CH}_{3} \mathrm{NO}_{2}$.

of $15 \mathrm{mM}{ }^{15} \mathrm{~N}_{2}$-urea, with or without $15 \mathrm{mM}$ tetrabutylammonium acetate in dimethylformamide/dimethyl sulfoxide- $d_{6}$ as a function of temperature (Figure 7). With acetate, the nitrogen resonance of urea was upfield by $1.2 \mathrm{ppm}$ at room temperature and $1.8 \mathrm{ppm}$ at $212 \mathrm{~K}$ relative to urea without acetate. These changes are consistent with structures 2 and/or $7 \mathbf{a} \rightleftarrows \mathbf{7 b}$, provided that hydrogen bonding, on the average, causes the nitrogen lone-pairs to become more delocalized and thus make 
the nitrogens more positive as the result of more $\mathrm{C}-\mathrm{N}$ double bond character. Generally, a positive double-bonded nitrogen has a reduced second-order paramagnetic effect at the ${ }^{15} \mathrm{~N}$ nucleus. ${ }^{19}$ However, although the changes in shift are not large, they are consistent with increases in intermolecular hydrogenbonding for urea alone and with increased acetate association with decreasing temperature.

Martin, Filleux-Blanchard, Martin, and $\mathrm{Webb}^{4}$ have suggested that the ${ }^{15} \mathrm{~N}$ chemical shifts of ureas can be related to $\Delta G^{\ddagger}$ for rotation by $\Delta G^{\ddagger}=79.60+0.2228 \delta^{15} \mathrm{~N}-1.7 I_{\mathrm{s}}$, where $\Delta G^{\ddagger}$ is in $\mathrm{kcal} / \mathrm{mol}, \delta^{15} \mathrm{~N}$ is the nitrogen shift referenced to $\mathrm{CH}_{3} \mathrm{NO}_{2}$, and $I_{\mathrm{S}}$ is a steric factor which is zero for unsubstituted urea. From this equation and the ${ }^{15} \mathrm{~N}$ shifts at $298 \mathrm{~K}$ (Figure 7), -307.10 and $-305.90 \mathrm{ppm}$, respectively, one predicts: $\Delta G^{\ddagger}$ $=11.18 \mathrm{kcal} / \mathrm{mol}$ for $15 \mathrm{mM}$ urea and $11.45 \mathrm{kcal} / \mathrm{mol}$ for 15 $\mathrm{mM}$ urea in the presence of $15 \mathrm{mM}$ TBA acetate. The agreement is reasonably good and the small predicted difference between urea alone and urea with acetate $(0.3 \mathrm{kcal} / \mathrm{mol})$ is consistent with our measurements (Table 3). For 1,1-dimethylurea in dimethylformamide solution, $\delta^{15} \mathrm{~N}$ is $-314.66 \mathrm{ppm}$ for the dimethyl nitrogen and $-307.53 \mathrm{ppm}$ for the unsubstituted nitrogen. ${ }^{20}$ These values combined with a steric effect ${ }^{4} I_{\mathrm{s}}$ of 1 , lead to predicted $\Delta G^{\ddagger}$ values for rotation of 7.79 and $9.38 \mathrm{kcal} /$ mol, respectively. These values are both somewhat larger and less widely separated than we observed experimentally. A different algorithm ${ }^{20}$ suggests respective values of $E_{\mathrm{A}}$ of 6.6 and $9.0 \mathrm{kcal} / \mathrm{mol}$, and these fit well with our values of $7 \pm 1$ and $9 \pm 1 \mathrm{kcal} / \mathrm{mol}$ (Table 3 ).

\section{Conclusions}

In this work, we have attempted to unravel influences on the rates of $\mathrm{C}-\mathrm{N}$ bond rotations in urea and thiourea where these entities act as hydrogen-bond donors rather than hydrogen-bond acceptors in solvents that, of necessity, are hydrogen-bond acceptors themselves. By studying the effects produced by acetate ion as a competitive hydrogen-bond acceptor, we have shown it is not likely that the differences between $\Delta G^{\ddagger}$ values for bond rotations predicted by ab initio calculations and those measured in solution are wholly due to solvent-urea or solvent-thiourea interactions.

\section{Experimental Section}

Sample Preparation. The ureas and thiourea were commercial materials and were dried in a vacuum desiccator overnight over

(19) Roberts, J. D. Rice University Studies 1980, 66, 147-178.

(20) Sibi, M. P.; Lichter, R. L. J. Org. Chem. 1979, 44, 3017-3022.

(21) McConnell, H. M. J. Chem. Phys 1958, 28, 430-431. phosphorus pentoxide prior to use. Urea, enriched $99.7 \%$ at both nitrogens, was purchased from Isotec. Tetramethylammonium and tetrabutylammonium acetates, from Aldrich, were stored and handled in a dry box. Deuteriodimethylformamide, dimethylformamide, and deuteriodimethyl sulfoxide were dried over molecular sieves overnight prior to use. Anhydrous dimethylformamide was obtained from Aldrich.

NMR Spectra. Variable-temperature NMR spectra were taken with a Bruker AM-500 NMR spectrometer. All other NMR spectra were taken with the same Bruker AM-500 or with a GE QE-300 NMR spectrometer. For variable-temperature experiments, the NMR probe temperature was calibrated using either the proton-shift difference between the $\mathrm{OH}$ and $\mathrm{CH}_{3}$ resonances of methanol (200 $\mathrm{K}$ to room temperature) or the proton-shift difference between the $\mathrm{OH}$ and $\mathrm{CH}_{2}$ resonances of ethylene glycol (room temperature to $400 \mathrm{~K}$ ). The ${ }^{15} \mathrm{~N}$ NMR experiments used $10 \%{ }^{15} \mathrm{~N}$-enriched nitromethane as an external chemical-shift reference. The ${ }^{1} \mathrm{H}$ NMR experiments were referenced to TMS or to the formyl proton of dimethylformamide at $8.03 \mathrm{ppm}$.

Calculations. The NMR line shape analyses for determining the rotation rates as a function of temperature used a True BASIC program based on the equations of McConnell ${ }^{21}$ to simulate line shapes with input of $\tau$, the characteristic lifetime of a given rotation state as well as the line widths and chemical shifts. Values for the latter two parameters were obtained by extrapolating the observed limiting line widths and the changes in the chemical-shift difference in the slowrotation regime into the temperatures of the intermediate-rotation regime. In the case of the line widths, this corrects as well as possible for temperature changes in quadrupole broadening of ${ }^{14} \mathrm{~N}$. Experimental spectra were matched to computer-simulated spectra by $\tau$ until a visual match was found as shown in Figure 1. The estimates of $\tau$ are believed to be $\pm 5 \%$ or better. The Arrhenius and Eyring parameters were calculated in the usual way with the Eyring transmission coefficient assumed to be unity. Uncertainties were calculated for the $95 \%$ confidence level.

Acknowledgment. This paper is dedicated on the occasion of his 80th birthday to Nelson J. Leonard, an inspiration and friend for more than 50 years. We are grateful to Peter Wei for assistance with the ${ }^{15} \mathrm{~N}$ NMR experiments as well as Linda Hanely and Francoise Gregoire for help with other NMR spectra. We also thank Steve Arvedson, Curt Hastings, and Dr. Robert Lee for technical consultations and useful conversations. This research was supported in part by the Caltech Summer Undergraduate Research Fellowships (SURF) to whom we are most appreciative. Further support was provided by the Arthur C. Cope Fund of the American Chemical Society and by Dr. and Mrs. Chester M. McCloskey.

JA961380K 